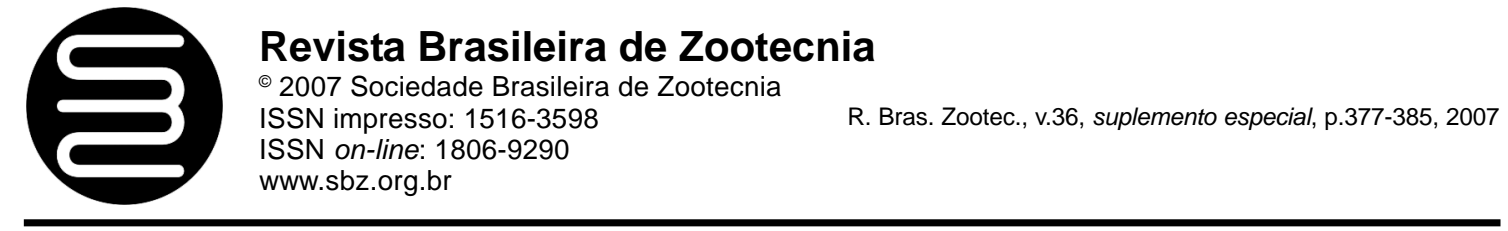

\title{
Desconstruindo um artigo científico
}

\section{Aloízio Soares Ferreira', Márvio Lobão Teixeira de Abreu²}

\author{
1 - Professor Titular do Departamento de Zootecnia do Centro de Ciências Agrárias da Universidade Federal de Viçosa - \\ alosofe@ufv.br \\ 2 - Professor Adjunto do Departamento de Zootecnia do Centro de Ciências Agrárias da Universidade federal do Piauí - \\ marvioabreu@ufpi.br
}

"Pedimos somente um pouco de ordem para proteger do caos.Nada é mais doloroso, mais angustiante do que um pensamento que escapa a si mesmo, idéias que fogem, que desaparecem apenas esboçadas, já corroídas pelo esquecimento ou precipitadas em outras, que também não dominamos [....] Perdemos sem cessar nossas idéias. É por isso que queremos tanto agarrarmo-nos a opiniões prontas." (Deleuze e Guattari)

\section{Introdução}

Desconstruir um artigo técnico científico pode parecer à primeira vista acintoso ou ruim, mas se pararmos para pensar um pouco e voltarmos os nossos olhares para a construção do conhecimento compreenderemos que a idéia de destruição, neste caso, é apenas a concepção de uma avaliação dos critérios da verdade. A epígrafe colocada para este tema foi escolhida no entendimento que ela passa a visão de que a publicação de um artigo científico deve expressar uma idéia nova sem opiniões prontas. Talvez esta tenha sido uma das maiores razões que levaram aos editores a buscarem auxílio dos cientistas no sentido da contribuição em forma de revisão de artigos.

Assim devemos compreender o revisor como um tipo de consultor que tem a função de aconselhar a revista ou periódico em relação ao padrão de qualidade do que se publica. Por isso compete ao consultor (revisor) emitir o seu parecer quanto ao valor do trabalho a ser publicado e ao EDITOR decidir se o trabalho deve ou não ser publicado. Isto não implica dizer que o revisor não possa emitir o seu parecer favorável ou não à publicação do artigo que avaliou.

A função de um periódico é de captar e armazenar para a posteridade os conhecidos gerados pela ciência. Esta tarefa hoje, num mundo globalizado, se tornou muito mais árdua, pois tem sido cobrada da comunidade científica a especialização em nível de mestrado e doutorado e tem sido cobrada dos doutores a produção ininterrupta de conhecimentos a serem divulgados em estrutura de artigos científicos. Verifica-se, portanto que em todas as áreas do conhecimento há um número expressivo de artigos produzidos. Alguns com grandes contribuições científicas e outros com contribuições menores. Por isso a necessidade de cada periódico definir ou escolher o que deseja publicar dentro dos seus conceitos de padrão de qualidade.

Além disto, há que se destacar que, face ao volume de informações a serem armazenadas, face às diversas línguas e linguagens existentes e ainda face à necessidade de universilazar o conhecimento tornou-se conveniente estabelecer regras rígidas e internacionalizadas para a publicação e expressão do conhecimento.

Destacamos, portanto a necessidade de se ter conhecimentos sobre o método científico e sobre as normas nacionais e internacionais para se proceder o processo de avaliação de um artigo científico. Por isso, antes de passar para as orientações a respeito do processo de desconstrução do artigo propriamente dito, apresentaremos um capítulo sobre a construção do conhecimento e comentaremos a trilogia da ciência (verdade - evidência - certeza) que norteia o fazer do cientista na comunicação dos resultados que produziu, pois os avaliadores não podem tergiversar na ignorância. 


\section{Problemas da construção do conhecimento científico}

\section{A verdade}

O problema da verdade radica na finitude do homem, de um lado, e na complexidade e ocultamento do ser da realidade, de outro lado. $\mathrm{O}$ ser das coisas e objetos que o homem pretende conhecer se oculta e manifesta-se sob múltiplas formas. Aquilo que se manifesta e que aparece em dado momento, não é a totalidade do objeto e nem da realidade investigada. $\mathrm{O}$ homem pode apoderarse e conhecer apenas aqueles aspectos do objeto que se manifestam, que se impõem, que se desvelam e isto ainda de modo imperfeito, pois ele não entra em contato direto com o objeto, mas apenas com a sua representação e impressão. A realidade toda de um objeto não pode ser captada por um investigador humano, quiçá, nem todos juntos alcançarão um dia desvendar todo o mistério do objeto investigado. Isto, porém não invalida o esforço humano na busca da verdade, na procura incansável de decifrar os enigmas do universo. Por isso, nunca se conhece toda a verdade qual seja, a verdade absoluta.

O desvelamento do ser das coisas supõe a capacidade de receber as mensagens e isto implica atenção, bons sentidos, bons instrumentos de trabalho e muita observação. O método e os instrumentos são as almas da pesquisa científica rumo à abertura do ser, à manifestação do ser, ao conhecimento da verdade.

Ocorre, ainda, que o homem, levado por certas aparências e sem o auxílio de instrumentos adequados, emite juízos precipitados que não correspondem aos fatos e à realidade e é por isso que temos o erro.

$O$ que é, pois a verdade? É o encontro do homem com o desvelamento, com o desocultamento e com a manifestação do ser (do objeto).

\section{A evidência}

As afirmações humanas erradas decorrem muito mais de atitudes precipitadas e da ignorância do homem em relação à natureza do ser que se oculta e se desvela fragmentariamente, do que da própria realidade.

A verdade só resulta quando houver evidência. Evidência é a manifestação clara do objeto, é transparência, é desocultamento, é desvelamento do ser. A respeito daquilo que se manifesta do ser pode-se dizer uma verdade. Mas como nem tudo se desvela de um ente, não se pode falar arbitrariamente sobre o que não se desvelou. A evidência, o desvelamento, a manifestação do ser é, pois, o critério da verdade.

\section{A certeza}

A certeza é o estado de espírito que consiste na adesão firme a uma verdade, sem temor de engano. Este estado de espírito se fundamenta na evidência, ou seja, no desvelamento do ser.

Relacionando o trinômio, poder-se-ia concluir dizendo: havendo evidência, isto é, se o objeto se desvelar ou se manifestar com suficiente clareza pode-se afirmar com certeza, ou seja, sem temor de engano, uma verdade.

Quando não houver evidência ou suficiente manifestação do objeto, o sujeito encontrar-se-á em outro estado de espírito, o que deve transparecer também na forma de expressar o objeto ou na linguagem falada e escrita. São os casos da dúvida, da ignorância e da opinião.

Ignorância é um estado de espírito puramente negativo que consiste na ausência de qualquer conhecimento relativo de um determinado objeto por falta de desvelamento. A ignorância pode ser: vencível, quando pode ser superada; invencível, quando não pode ser superada e culpável, quando há a obrigação de fazê-la desaparecer.

A dúvida é um estado de espírito onde se verifica o equilíbrio entre a afirmação e a negação. A dúvida é espontânea quando o equilíbrio entre a afirmação e a negação resulta da falta do exame entre os prós e os contras. A dúvida refletida é o estado de equilíbrio que permanece após o exame das razões prós e contras. A dúvida metódica consiste na suspensão fictícia ou real, mas sempre provisória, do assentimento a uma afirmação tida até então por certa para lhe controlar o valor. A dúvida universal consiste em considerar toda afirmação como incerta, é a dúvida dos céticos.

A opinião se caracteriza pelo estado de espírito que afirma com temor de enganar-se. Já se afirma, mas de tal maneira, que as razões em contrário não dão uma certeza. O valor da opinião depende da maior ou menor probabilidade das razões que fundamentam a afirmação. 


\section{O conhecimento}

A preocupação do cientista é chegar a verdades que possam ser afirmadas com certeza e chegar ao conhecimento das verdades. $\mathrm{O}$ conhecimento se dá de duas formas: por intuição e por conhecimento discursivo.

A intuição é uma forma de conhecimento imediato, um tipo de pensamento presente no espírito humano que é atingido sem intermediários. Intuição então pode ser conceituada como sendo uma visão súbita. Na metodologia científica, a intuição pode ser considerada como ponto de partida do conhecimento, da possibilidade da invenção, da descoberta ou dos grandes saltos do saber humano.

O conhecimento discursivo é aquele que se dá de forma mediata, ou seja, aquele que se dá por meio de conceitos. Este tipo de conhecimento opera por etapas do pensamento, por encadeamento de idéias, juízos e raciocínios que levam a determinada conclusão. Então o conhecimento se dá pela razão e a razão precisa realizar abstração e abstrair é isolar, é separar de.

Assim nos remetemos à tarefa de propor o debate sobre como desconstruir um artigo técnicocientífico ou sobre como avaliar um artigo técnicocientífico.

\section{Como avaliar um artigo técnico-científico}

Iniciamos este capítulo baseando-nos na concepção de que revisores de artigos técnicocientíficos devem ser pessoas experientes, conhecedoras do processo de construção do conhecimento e, portanto, conhecedoras do método científico. Por isso o que estaremos expondo aqui é a nossa experiência acumulada ao longo dos anos como revisores de artigos para periódicos de diferentes áreas do conhecimento.

É necessário também se relevar que a nossa experiência estará traduzida na forma de orientações que visam contribuir para a melhoria do processo de revisão dos artigos a serem publicados na RBZ e que podem também ser aplicada a artigos destinados a outros periódicos.

Revisar um artigo é avaliar o pensamento de algumas pessoas traduzido na forma escrita, ou seja, é avaliar a forma de expressão da relação de um pesquisador com o objeto de sua pesquisa, e por isso é um processo subjetivo e necessita de atenção e isenção totais do avaliador. Assim entendemos que revisar demanda que o avaliador primeiro descubra ou tente descobrir o que foi pensado, o objeto da pesquisa que está em processo de avaliação, para em seguida se descobrir se o que está escrito expressa a idéia do que foi pensado.

Desta forma, para avaliar um artigo, a primeira coisa a se fazer é uma leitura, de certo modo dinâmica, do artigo na íntegra, sem interrupções, para se checar se não há exageros e nem incompatibilidades com a fôrma da revista, para em seguida ou em momento novo, se fazer leituras detalhadas e em partes do que se pretende avaliar.

A trilogia verdade - evidência - certeza deve ser apresentada em três momentos diferentes no artigo. A verdade relativa, aquela obtida da relação do pesquisador com o objeto de sua investigação, deve estar expressa na INTRODUÇÃO. A evidência, expressada na forma da interpretação dos resultados e do diálogo com a comunidade científica, deve estar contida na DISCUSSÃO. A certeza deve ser expressa na forma de CONCLUSÃO.

\section{Avaliação do capítulo introdutório}

A introdução de um artigo é o local onde os cientistas apresentam a sua relação com o objeto da pesquisa, a sua relação com a verdade a ser modificada e a sua habilidade e sua competência científica. Por isso, este capítulo deve ser de suma importância para o pesquisador. É nele que os cientistas redigem de maneira clara, concisa, coerente e lógica, em no máximo duas laudas, os seus conhecimentos sobre o objeto de sua pesquisa expressos na forma de conceitos.

Assim o revisor precisa emitir em primeiro lugar a sua opinião sobre o processo de construção do conhecimento, qual seja se o artigo avaliado foi construído com bases científicas e, portanto se traduz em novos conhecimentos.

Mas como um revisor pode emitir esta opinião?

Relendo com muita atenção e cuidado o capítulo introdutório e buscando a relação do que está expresso nele com o processo de teste da hipótese, com os resultados obtidos e com a conclusão.

$\mathrm{O}$ delineamento experimental ou as técnicas usadas para aceitar ou refutar uma hipótese

๑๐ 2007 Sociedade Brasileira de Zootecnia 
decorrem das premissas e estas devem estar na introdução. A conclusão decorre da aceitação ou não das hipóteses e estas são inferências dedutíveis ou indutíveis que decorrem das premissas.

No capítulo introdutório, o revisor deve checar se os autores demonstraram ter conhecimento do objeto da pesquisa, se as premissas estão devidamente apontadas e se a(s) hipótese(s) está condizente com as premissas. Se estas coisas estiverem em seus devidos lugares, os objetivos dos autores estarão expressos com clareza no último parágrafo do capítulo introdutório.

Comece a duvidar do processo de construção do conhecimento, no capítulo introdutório se:

1 -os verbos estiverem em tempo presente,

2 - a verdade estiver expressa na idéia de outrem e não dos autores,

3 - a adjetivação predominar,

4 -nele contiverem muita história e poucos conceitos e

5 -o objetivo tiver tautologicamente sido remetido para o trabalho e escapado dos autores.

$O$ verbo firmado em tempo presente caracteriza verdade absoluta. A verdade absoluta é dogma. As verdades absolutas evidenciam a não necessidade de pesquisa ou de novos conhecimentos sobre $\mathrm{o}$ assunto. O tempo dos verbos no capítulo introdutório deve ser preferencialmente o pretérito, ou seja, a verdade deve ser apresentada de forma condicional, pois ela está na condição da relação dos pesquisadores com o conhecimento a ser modificado.

Não se deve usar revisão inútil, do tipo, segundo Fulano de tal (2007), porque a introdução é o local da expressão de conceitos e não de fatos. Devemos lembrar que o artigo científico deve ser redigido seguindo-se a técnica de redação dissertativa, qual seja com parágrafos expressos na forma de sucessão de idéias. Do fato, o pesquisador deve extrair a idéia e transformá-la em conceito de modo concreto. Não queremos dizer com isto que citações não podem estar contidas neste capítulo, pelo contrário, queremos dizer que na relação do pesquisador com o objeto da pesquisa muito foi apreendido com a relação dos outros pesquisadores com o mesmo objeto. É por isso que todos os conceitos devem estar calcados e sustentados em e por alguém (Fulano de tal, 2007).
Destacamos que, embora o artigo científico tenha uma estrutura dissertativa, existem nele dois momentos de uso da técnica de redação descritiva, quais sejam o capítulo metodológico e a apresentação dos resultados.

Adjetivos são palavras que expressam conceitos abstratos e os abstratos são relativos e por isso não devem perpassar na relação do homem com o objeto de sua pesquisa. O que é bom para alguém pode ser ruim para outros e o que é grande num dado momento pode deixar de ser em outro.

$\mathrm{O}$ revisor, em sua isenção e imparcialidade, não deve ser impertinente com coisas banais. Entretanto, implicar com erros tautológicos do tipo o objetivo deste trabalho foi não se constitui em impertinência, pois temos constatado que erros desta natureza em mais de noventa por cento dos casos estão associados à falta de percepção dos autores em relação ao objeto de suas pesquisas e em cerca de trinta por cento deles, a tautologia ostenta erros metodológicos profundos, que levam à recomendação da refuta do trabalho.

\section{Avaliação do título do artigo}

Avaliado o capítulo introdutório, deve o revisor se transportar para o título. O título, por ser o primeiro indexador bibliográfico de uma publicação, reveste-se de grande importância, pois ele deve expressar com clareza e de maneira sucinta o objeto da pesquisa. A sua relação é estreita e direta com o objetivo. Nele deve estar contida a idéia de um todo, pois ele é o primeiro resumo da idéia.

Como indexador, não deve conter caracteres indesejáveis como pontuação de qualquer natureza (ponto, dois pontos, vírgula, aspas, ponto e vírgula, interrogação, exclamação), nem sinais (parêntesis. $+,-,=, X, x, *, \&, /, \#)$ e muito menos chamadas. O título também não deve conter informações de local e quantidade (numerais) e ainda expressões inúteis tais como considerações sobre, estudo de, utilização de, estimação de, estimativa de, análise de, e tantas outra que não agregam informações importantes ao entendimento do conteúdo do artigo.

Como resumo, não pode conter parâmetros e, se o objeto da pesquisa for de causalidade direta com algum fenômeno, ele deve expressar com clareza e precisão esta causalidade, qual seja a 
informação do efeito de que sobre o que. A relação de conseqüência das conseqüências não é de causalidade direta. Podemos estabelecer a relação da fitase com a absorção de fósforo, mas não podemos estabelecer a relação da fitase com características ósseas. Por isso, alguém que estude a inclusão de fitase em dietas com ingredientes contendo fósforo fitico, não pode colocar em seu artigo o título de efeito da fitase sobre características ósseas de determinada espécie. O título neste caso deveria ser: Fitase em dietas contendo tal ingrediente para tal espécie animal. Os parâmetros (ganho de peso, deposição de cálcio e fósforo nos ossos, resistência óssea e outros) neste caso devem ser usados como informações balizadoras do critério da verdade e não constituem o objeto da pesquisa.

A parametrização do título, com raras exceções, leva a produção de dois ou mais artigos por uma única idéia de pesquisa (leva àquilo que costumamos chamar de produção de filhotes de artigos). Os parâmetros devem ser compreendidos como medidas de aferição e estabelecimento dos critérios da verdade (da evidência). Geralmente eles são produtos da relação de causalidade (direta e indireta) das variáveis testadas para comprovação de uma hipótese com o objeto da pesquisa. Por isso, eles devem ser vistos no todo em cada uma das pesquisas e não podemos admitir que uma pesquisa única para comprovação de uma única hipótese sirva para produção de dois ou mais artigos científicos, porque nestas circunstancias os artigos deixam de ser científicos.

Novamente damos destaque à necessidade de o revisor checar a cientificidade e a necessidade da pesquisa que ele está apreciando na forma de artigo científico.

\section{Avaliação do capítulo metodológico}

O próximo passo a ser dado, após as análises do capítulo introdutório e do título, é checar o método usado para testar a(s) hipótese(s).

O capítulo metodológico deve ser analisado considerando-se que a sua elaboração guarda estreita relação com a seqüência do fazer, ou seja, com o que foi feito.

$\mathrm{Na}$ Zootecnia, normalmente as pesquisas são realizadas em experiências com tratamentos e desenhos experimentais bem definidos a priori e os métodos que se têm utilizado são o hipotético- dedutivo ou o hipotético-indutivo. Entretanto em algumas áreas específicas da Zootecnia, como a de melhoramento animal, a maioria das pesquisas são realizadas por meio de experiências que não seguem o padrão de desenhos experimentais e nestes casos o método que mais tem sido usado é o analítico modelar.

Assim recomendamos que a primeira coisa que se averigüe e identifique é que método está sendo usado.

A propósito vamos abrir aqui um parêntesis para considerações sobre a fôrma da Revista Brasileira de Zootecnia que designa o capítulo metodológico de Material e Métodos. Esta designação traz em si dois grandes equívocos, pois material é uma palavra substantiva coletiva que designa os objetos (bens materiais), ou seja, neste caso, material representa o coletivo dos objetos usados na pesquisa e por isso só pode estar no singular. Estes objetos são parte do método e por isso não podem ou devem estar em destaque. Entretanto, o método, por ser processo em construção, e dele faz parte o material, por isso ele é único e só pode ser expresso no singular. Recomendamos que nesta Reunião Anual da Sociedade Brasileira de Zootecnia façamos uma reflexão sobre isto e modifiquemos a designação deste tópico para Metodologia ou simplesmente para Método, pois o que se releva nele é a descrição do método usado.

Isto posto, retomamos a consideração sobre a análise do capítulo em si. O revisor, após identificar o método, deve verificar se os autores o elaboraram numa seqüência lógica. Vou descrever a seqüência que é a mais lógica para experiências com desenhos experimentais rígidos, pois é este tipo de experimento que predomina nas Ciências Zootécnicas. O olhar do revisor, em primeira instância, deve se voltar para a lógica seqüencial dos fatos descritos.

A primeira coisa a ser descrita, lembrando que a técnica redacional usada neste capítulo é a descrição, é o local, pois é dele que decorrem as condições experimentais e é com base nele que é estabelecido o desenho experimental. Por isso que a segunda coisa a ser descrita é o desenho experimental (delineamento experimental). É a partir do delineamento que estipulamos tratamentos, repetição, unidade experimental e animais, plantas, área a ser cultivada, etc.

${ }^{\circledR} 2007$ Sociedade Brasileira de Zootecnia 
Descrito o delineamento experimental, os autores devem cuidar da descrição de manejo, dos modelos, das técnicas e dos processos usados para a coleta de dados e obtenção dos resultados, seguindo-se a ordem cronológica em que foram realizadas tais coisas. Descrito isto, por fim, os autores descrevem como foram analisadas as informações obtidas. Desta forma, o revisor deve adentrar na lógica de quem escreveu e realizar a sua análise relevando-a.

Este capítulo deve ser descrito na forma seqüencial, sem subdivisões inúteis, que só servem para aumentar espaços em branco e quebrar a estrutura organizacional do texto. Senão vejamos por quê? Ao colocarmos um subtítulo denominado Animal e descrevermos sobre ele: foram usadas 200 vacas de leite com peso de $450 \mathrm{~kg}$ cada uma delas divididas em quatro tratamentos; devemos nos perguntar: o verbo (foram), o numeral (duzentos), a unidade de massa $(450 \mathrm{~kg}$ ) pertencem a qual categoria animal? E os tratamentos por acaso são animais? Se subdividirmos, deveríamos então colocar da seguinte maneira: Animais vacas leiteiras, Peso - $450 \mathrm{~kg}$, etc., etc., etc.

Daí uma pergunta importante a ser feita pelo revisor, qual seja: a desorganização descritiva é fator decisivo para a recomendação da recusa de uma publicação? A resposta é não, pois compete ao revisor apontá-la e aos autores acatar ou não as sugestões que julgarem relevantes.

Então o que pode levar o revisor a recomendar a refuta ou aceitação de um artigo? É a lógica estabelecida entre as hipóteses e o método de seu teste. O que se percebe é que, na maioria das vezes, quando autores não têm clareza do objeto de sua pesquisa, eles também não as têm em relação ao método e é por isso que a descrição lógica e cronológica do método não é realizada. Assim, voltamos à pergunta anterior, e propomos que o revisor deve respondê-la considerando este aspecto.

Aproveitamos a oportunidade que nos foi dada para apresentar este tema para debate e analisamos os artigos publicados na Revista Brasileira de Zootecnia (RBZ) entre janeiro de 2001 a dezembro de 2006. Constatamos que $28,0 \%$ deles continham erros metodológicos sérios, sendo que destes $58,0 \%$ eram impublicáveis (decisão a ser tomada pelo Editor), enquanto que os demais poderiam ter as suas análises estatísticas refeitas para novas interpretações e outras conclusões.
Os erros da relação dos tratamentos com a forma de se testar as hipóteses têm se tornados constantes e gritantes. Eles saltam aos olhos. Vamos nos atrever, sem citar nomes, registrar dois deles. Em um deles os autores tentaram estabelecer uma relação entre o peso dos animais ao desmame com a produção de leite deste mesmo animal após o parto, quando adulto (o que é pouco provável ou se provável, pouco evidente), e para comprovar esta hipótese, os autores categorizaram os animais por peso após o desmame e por tipo de alimentação que receberam enquanto cresciam até se tornarem reprodutores. Neste caso, se houvesse, e havia, correlação entre o peso do animal e a alimentação seria conveniente que os tratamentos fossem organizados em desenho fatorial e não o foram. $\mathrm{O}$ que foi pior, o trabalho foi discutido com base em resultados tabulados na forma da correlação dos nutrientes do leite com outras coisas que não tinham nada a ver com o objeto da pesquisa. Este trabalho foi publicado pela RBZ e o que é pior, tem servido de modelo para outros, porque os autores são referências neste segmento zootécnico.

Num outro trabalho, os autores distribuíram os tratamentos em um experimento de forma fatorial $2 \mathrm{X} 2 \mathrm{X} 2$, mas quando tabularam os resultados descobriram que só tinham seis tratamentos e os apresentaram em seis tratamentos (dieta úmida, dieta seca, dieta com palatabilizante, dieta sem palatabilizante, água com palatabilizante e água sem palatabilizante). Neste caso ao contrário do anterior não se constata correlação entre os fatores.

A razão destas confusões reside no fato da falta de clareza do objeto das pesquisas. No primeiro caso supra relatado, queremos crer que existiam vários objetos de pesquisa e os autores se perderam em isolá-los. No segundo caso, os autores tinham como objeto o consumo de ração e se perderam ao considerar que o objeto era o palatabilizante ou a adição de palatabilizante, ou ainda o tipo de alimentação (líquida ou sólida).

Poderíamos enumerar aqui vários outros artigos, publicados ou não publicados em função de nossa avaliação e nossa recomendação da não publicação, com equívocos científicos profundos, mas preferimos ficar somente nestes dois exemplos porque o objetivo aqui é apenas demonstrar como deve proceder o revisor. Destacamos ainda que alguns destes equívocos não são exclusividades 
de pesquisadores brasileiros, pois eles também estão explicitados por estrangeiros em revistas estrangeiras.

\section{Avaliação dos resultados}

Esta talvez seja a parte mais fácil de avaliar, pois ao chegar neste ponto, a opinião do revisor sobre o trabalho já deve estar formada.

Aqui também vamos abrir um parêntesis para sugerir ao editor da Revista Brasileira de Zootecnia que mude a estrutura da revista via separação dos capítulos de apresentação dos resultados daquele relativo à discussão. Esta é uma tendência das revistas periódicas nacionais e internacionais classificadas como A no qualis da CAPES. Esta separação permite que os autores vislumbrem as suas pesquisas no todo e viabiliza o exercício da discussão com o estabelecimento dos critérios da verdade, além de possibilitar de forma inequívoca o relacionamento dos novos achados com a nova verdade a ser anunciada. Este exercício possibilitará ainda aos autores uma visão científica que os levará a não produção de artigos filhotes, pois será necessária a inter-relação entre os fenômenos e os parâmetros.

O revisor, neste capítulo, deverá apenas checar se os resultados obtidos são condizentes com as condições experimentais e, portanto oferecem condições para novas descobertas.

Assim aqui só cabe avaliar se os resultados merecem ou não ser divulgados e se estão corretamente e adequadamente apresentados. Avalia-se, portanto se os gráficos, tabelas, figuras diagramas são necessários e estão bem elaborados. É muito importante otimizar os espaços úteis de uma revista e por isso, não é necessário apresentar a representação gráfica de uma regressão linear, porque para todos os leitores uma linear crescente traz à visão do leitor instantaneamente uma linha reta inclinada em posição ascendente.

\section{Avaliação do capítulo da discussão}

Neste item, compete ao revisor checar se os resultados foram efetivamente discutidos. A discussão é o estabelecimento dos critérios da verdade e por isso muito mais do que comparar resultados, mistér se faz estabelecer a relação deles, de forma analítica, com o que foi verificado por outros em outras condições experimentais.
A discussão deve ultrapassar a fronteira das comparações, até porque, os resultados iguais em condições diferentes podem torná-los diferentes ou mantê-los iguais, enquanto que os resultados diferentes em condições semelhantes podem tornálos iguais ou mantê-los diferentes.

Têm sido comuns as comparações indevidas. No levantamento que fizemos nos artigos publicados pela RBZ entre 2001 e 2006 constatamos que em $92,0 \%$ deles havia pelo menos uma comparação indevida, ou seja, inadequada e errada. Dizer que o ganho de peso obtido com os animais nesta pesquisa foi similar ou semelhante aos obtidos com os animais de idades diferentes, pesos diferentes, fases diferentes, submetidos a condições experimentais diferentes, em momentos diferentes e a outros diferentes é o mesmo que não dizer nada. Cabe sempre uma pergunta e daí? É preciso responder se as diferenças possibilitam inferências que levam a uma nova verdade.

Inferir é por definição metodológica passar das premissas para a conclusão. Volto à questão da revisão, e pergunto, se os autores não foram capazes de inferir ou discutir os seus resultados, $o$ artigo deve ser refutado? A resposta é novamente não e aqui ao contrário do capítulo anterior, o revisor não deve ousar a sugerir a discussão, pois esta é uma questão exclusiva dos autores. Os revisores devem se ater na emissão de sua opinião informando que os resultados precisam ser discutidos, mas se os autores desejam manteremse na ignorância, este é um direito deles.

Para não sermos mal interpretados, reapresentaremos aqui o conceito científico de ignorância, qual seja a ignorância é a falta de conhecimento de um determinado assunto e como as verdades radicam da relação do cientista com o objeto a ser conhecido, todos os cientistas são portadores temporários de ignorâncias.

A decisão do revisor em relação ao capítulo discursivo é no sentido de certificar-se se os dados, em face de confiabilidade, merecem ser publicados e se os resultados permitem conclusões que contribuam para construção de novos conhecimentos.

\section{Avaliação da conclusão}

$\mathrm{O}$ avaliador deve certificar-se se os autores foram capazes de tirar conclusões decorrentes da

${ }^{\circledR} 2007$ Sociedade Brasileira de Zootecnia 
sua hipótese. Neste item não se admite nenhuma ilação do tipo; com base nos resultados é possivel concluir que ou os resultados permitem concluir que.

As conclusões devem ser apresentadas com o verbo no presente e não podem ser confundidas com os resultados. Muito menos podem ser apresentadas na forma hipotética.

A confusão de se apresentar os resultados como conclusões têm sido uma das razões da subdivisão de trabalhos do tipo filhotes.

Se as conclusões não estiverem corretas compete ao revisor corrigi-las e apresenta-las aos autores indicando ao editor que $o$ aceite do artigo para a publicação está condicionado à correção da conclusão.

\section{Avaliação geral}

Cumpridas estas etapas cabe ao revisor checar se o resumo representa ou efetivamente expressa o conteúdo sucinto do trabalho. O resumo deve ser elaborado sem abreviaturas e sem parágrafo. Nele devem estar contidos os objetivos, a forma de teste da hipótese, os resultados que levaram aos autores a conclusão e a própria conclusão.

Após o resumo devem ser apresentadas palavras-chave e estas não podem estar apresentadas no título, pois ambos, título e palavraschave são indexadores.

Outra coisa a ser checada pelo revisor é se o artigo contém marcas comerciais que são inadimissíveis em qualquer ponto de um artigo científico. Se alguma empresa doou algum tipo de produto para a viabilização da pesquisa devese fazer a ela o agradecimento pela doação, especificando o que foi doado. Se algum equipamento, modelo ou tecnologia foi usado cabe a explicitação do funcionamento ou processo e não da marca comercial.

Assim o item agradecimento pode e deve estar presente em um artigo científico e ele deve ser localizado sempre após as conclusões. Também é no item agradecimento que se faz menção aos agentes financiadores da pesquisa.

Após a apresentação da autoria do trabalho deve ser colocado o endereço dos autores.

Vamos dar mais uma sugestão ao editor da RBZ, qual seja, não coloque que o artigo fez parte de uma tese e muito menos desqualifique os autores informando que eles são estudantes de

${ }^{\circledR} 2007$ Sociedade Brasileira de Zootecnia mestrado ou doutorado, pois isto é condição transitória de suas vidas. Eles são profissionais e devem estar indicados como qualificados profissionalmente. Assim, Fulano de Tal deve ser anunciado como Zootecnista, Engenheiro Agrônomo, Médico Veterinário, ou outra, se eles ainda não tiverem endereço fixo e estiverem na condição de pós-graduando. Por isso tenho sido defensor de que o endereço dos autores deve ser apresentado na forma de endereço eletrônico e não de endereço comercial.

O revisor não deve gastar o seu tempo procurando no artigo defeitos na apresentação de citações bibliográficas e se as bibliografias citadas no texto estão referenciadas no item Literatura Citada, pois esta deve ser uma tarefa de funcionários da revista. A única coisa que o revisor deve checar em termos de citações bibliográficas é se os autores cometeram o equívoco de ler com os olhos dos outros, qual seja, de fazerem citação de citação do tipo Fulano de tal (2006) citado por Beltrano de tal (2005). Este tipo de citação é proibido internacionalmente. Em um tempo de globalização da informação não se admite que os autores não consigam recuperar uma informação.

Feito a tarefa da forma que acabamos de expor, deve o revisor emitir o seu parecer conclusivo sobre $\mathrm{o}$ artigo que ele avaliou.

\section{Desconstruir sim, mas com ética}

Algumas pessoas têm reclamado dos pareceres emitidos por alguns revisores e o mote da reclamação destas pessoas é que os revisores têm faltado com a ética na emissão de seus pareceres. É possível que algumas verdades, do ponto de vista dos revisores, possam soar em tom agressivo, entretanto quando estas verdades não podem ser contestadas, elas devem ser encaradas pelos autores como esclarecimentos necessários para a compreensão do processo de redação de um artigo científico. Desqualificar o que não tem qualidade não é antiético, pelo contrário, mostrar a verdade que desvela ignorâncias vencíveis e invencíveis e até mesmo culpáveis é ético e necessário. Ocorre que esta é uma tarefa árdua e difícil e muitos revisores não têm tido paciência ou tempo para cumpri-la de maneira polida e educada.

Antiético são os pareceres de revisores, que decorrem da ignorância deles em relação ao objeto 
de estudo, que os fazem imputar erros no artigo. O pior é que eles ainda insistem em não permitir que o artigo seja publicado. Tem revisores que insistem em exigir análises de variância da conversão alimentar e outros parâmetros que não obedecem a distribuição normal. Tem revisores que querem que se façam análises não paramétricas de informações paramétricas. Tem revisores que insistem que dois experimentos realizados de forma independente e em fases separadas sejam analisados e publicados em um só artigo. Tem revisores que insistem em exigir análises laboratoriais de aminoácidos disponíveis. Tem revisores que insistem que as suas correções e sugestões, mesmo as de ordem de estilo ou de menor importância para o contexto geral da produção do conhecimento, devem ser obrigatoriamente acolhidas pelos autores. Esta insistência consiste sim em falta de ética. Recoloco a idéia de que revisores são conselheiros do editor e que a decisão de se publicar ou não é do editor.

Corrigir erros não é antiético. Imputar erros ou não corrigi-los constituem sim falta de ética e compromisso.

Neste momento, em que estamos falando de ética, gostaríamos de destacar algo importante que estrategicamente deixamos para fazê-lo ao final. O revisor deve, sobretudo, ao ter aceitado a tarefa de avaliar, ter se certificado de sua competência para tal, ou seja, ter se certificado se tinha ou não domínio sobre o assunto a ser avaliado. Destacamos ainda que a principal função do avaliador é a de buscar razões para aceitar o artigo e que quem refuta o artigo são os autores que não apresentam razões convincentes e qualitativas para $o$ aceite.

Cremos com isto ter dado a nossa contribuição ao debate sobre a melhoria de qualidade para a Revista Brasileira de Zootecnia.

\section{Literatura citada}

ARANHA, M.L.A.; MARTINS, M.H.P. Filosofando: introdução à filosofia. $3^{\mathrm{a}}$. Ed., São Paulo, Editora Moderna, 439p. 2003

CERVO, A.L.; BERVIAN, P.A. Metodologia científica. $3^{\mathrm{a}}$ Ed. São Paulo, Editora Mac Graw-Hill do Brasil, 249p. 1983

DELEUZE, G.; GUATTARI, F. O que é filosofia? $2^{\text {a }}$. Ed. Rio de Janeiro, Editora 34, 288p. 1992

FEITOSA, V.C. Redação de textos científicos. $5^{\text {a }}$. Ed. Campinas, Editora Papirus, 155p. 1991

FIGUEIREDO, L.C. A redação pelo parágrafo. Brasília, Editora Universidade de Brasília, 128p. 1998
LAKATOS, E.M.; MARCONI, M.A. Metodologia científica. São Paulo, editora Atlas, 231p. 1983

SANTOS, R.S. Metodologia científica: a construção do conhecimento. $3^{\mathrm{a}}$. ed., Rio de Janeiro; DP\&A editora,144p., 2000.

VOLPATO, G.L. Ciência: da filosofia à publicação. $4^{\mathrm{a}}$. Ed., Botucatu, Tipomic editora, 204p., 2004. 